\title{
Atividades institucionais da extensão rural pública para a formação dos jovens na Zona da Mata Mineira
}

\author{
Douglas Vianna Bahiense ${ }^{1}$ \\ João Paulo Louzada Vieira ${ }^{2}$ \\ Marco Paulo Andrade ${ }^{3}$ \\ Margareth do Carmo Cruz Guimarães ${ }^{4}$
}

\begin{abstract}
RESUMO
A juventude rural, que até então era invisível nas políticas públicas, passa a ter protagonismo como novo ator social demandante de ações e estratégias específicas. Dito isso, o objetivo deste artigo é analisar os mecanismos institucionais de Assistência Técnica e Extensão Rural (ATER) na aplicação das políticas públicas para os jovens rurais. Para tal, realizou-se pesquisa documental com base nos relatórios elaborados no Projeto Transformar, desenvolvida pela Empresa de Assistência Técnica e Extensão Rural do Estado de Minas Gerais (EMATER-MG), no período de 2006 a 2012, e a Semana da Juventude Rural, realizada na Universidade Federal de Viçosa (UFV), no período de 2009 a 2019, além de entrevistas com os funcionários públicos da EMATER-MG. O Projeto Transformar, apesar dos dados incompletos, esta política pública atendeu a maioria dos municípios da Zona da Mata. A Semana da Juventude Rural teve maior relevância devido à logística, maior espaço da Universidade e à distribuição das oficinas em diferentes áreas temáticas, dentre as quais se destacam Engenharia Agrícola, Construção Civil e Fitotecnia. Em relação ao corpo técnico, os servidores explanaram os pontos fortes das duas políticas públicas analisadas, sobretudo, através dos cursos ministrados, para que os jovens alcancem sua autonomia.
\end{abstract}

Palavras-chave: Políticas Públicas; EMATER-MG; Projeto Transformar; Semana da Juventude Rural.

\section{Institutional activities of public rural extension for youngers learning of Mata Mineira Zone}

\begin{abstract}
The rural youth, that until then it was invisible in publics policies, it stay has protagonism like new social actor to need actions and specifics strategies. Said that, the goal the paper is analyze the institutionals tools for Technical Assistence and Rural Exttention (TARE) in the application of public policy for field youngs. For such, it was performed documental research based on the reports prepared in Transofrm Project, desenvolvida pela Technical Assistance and Rural Extension Company of Minas Gerais State (EMATER-MG), between 2006 and 2012, and the The Field Youth Week, realized in Federal University of Viçosa (UFV), between 2009 and 2019, besides interviews public workers of EMATER-MG. The Transform Project, although incomplete data, this public policy served the most cities of Zona da Mata. The Field Youth Week had greater relevance because the logistics, bigger space of university and distribution of workshops in diferentes thematic areas, among highlight the Agricultural Engineering, Civil Building and Plant Sciences. About technical staff, the servers explain in the strong points two public politics analyzed, mainly, through training given, so that young people achieve their autonomy.
\end{abstract}

Palavras-chave: Public Policy; EMATER-MG; Transform Project; Field Youth Week.

\footnotetext{
${ }^{1}$ MSc. Produção Vegetal pela Universidade Estadual Norte Fluminense Darcy Ribeiro (UENF); Laboratório de Engenharia Agrícola (LEAG-UENF); douglas.bahiense@yahoo.com.br

${ }^{2}$ MSc. Extensão Rural pela Universidade Federal de Viçosa (UFV); Departamento de Economia Rural; joaopaulo.direito@yahoo.com.br

${ }^{3}$ MSc. Extensão Rural pela Universidade Federal de Viçosa (UFV); Departamento de Economia Rural; andrade.marcop@gmail.com

${ }^{4}$ Especialização em Extensão Rural para o Desenvolvimento Sustentável na Universidade de Brasília (UNB); Graduação em Pedagogia pela Faculdade de Filosofia Ciências e Letras de Colatina-ES (FAFIC); Coordenadora Técnica Regional da Empresa de Assistência Técnica e Extensão Rural de Minas Gerais (EMATER-MG); margareth.guimaraes@emater.mg.gov.br
} 


\section{INTRODUÇÃO}

Com a retomada da democracia no Brasil na década de 1980 e, especialmente, após a promulgação da Constituição de 1988, ocorreu um reordenamento do Estado brasileiro, reduzindo o poder central das ações governamentais com objetivo de ampliar o acesso aos recursos e às políticas públicas. Como resultado desses processos de descentralização pode-se citar a estruturação nos Estados e Municípios e dos conselhos gestores de políticas públicas e a formação de agendas com enfoque territorial, regional e local de desenvolvimento (MATTEI, 2014).

Em meio a essas reformulações, Grisa e Schneider (2014) identificaram as principais abordagens das políticas públicas destacadas para o meio rural, principalmente aquelas destinadas à agricultura familiar, que se iniciaram por volta dos anos 1990. Historicamente, podem-se identificar três fases nessas políticas com suas agendas e objetivos específicos: a primeira, que visava o aumento de produtividade pelo ideário desenvolvimentista no período de 1950 até 1990; a segunda, formulada após a Constituição de 1988 e voltada para o assistencialismo rural; e a terceira, a partir dos anos 2000, orientada pela formação de mercados alimentares e para o desenvolvimento rural sustentável.

De modo geral, a partir da década de 1990, o Governo Brasileiro teve dedicação na reestruturação das políticas públicas na agricultura tendo como os principais beneficiários os agricultores familiares e demais categorias sociais pertencentes no campo. Essa inclusão indica a reorientação de três diretrizes nas políticas passadas: a divisão paradoxal das ações, de um lado a finalidade produtiva e do outro a finalidade assistencial; as dificuldades de acesso da ampla parcela de pequenos produtores às políticas de fomento da produção agropecuária e a inexistência de considerações socioambientais nas políticas de desenvolvimento (CAZELLA et al, 2016).

$\mathrm{Na}$ área da oferta de serviços públicos, observam-se significativas mudanças na filosofia estratégica de ação da Assistência Técnica e Extensão Rural (ATER). Tais transformações contestam o modelo tecnológico pronto e verticalizado; os conceitos e procedimentos metodológicos, em especial o conceito universal de desenvolvimento; a função atribuída à instituição/organização pública, privada e não governamental; e ampliação dos segmentos sociais beneficiários da ATER ${ }^{5}$. Como exemplo de renovação da Extensão Rural brasileira, é elaborada uma nova Política Nacional de Assistência Técnica e Extensão Rural (PNATER), redigida em 2003 e publicada em 2004, com o objetivo de ampliar a oferta dos serviços públicos. Na nova política, ganham maior importância os processos formativos de agentes de ATER (agricultores familiares, técnicos, lideranças políticas e sindicais e outros funcionários) e o uso de diagnósticos rurais participativos, por exemplo (MARINHO; FREITAS, 2015).

Além de ampliar e especificar os novos beneficiários de ATER, essas políticas públicas instituídas também enfatizam a necessidade de se avançarem suas diretrizes de trabalho para melhor atender o público rural, levando-se em consideração as perspectivas de gênero e geração. A juventude rural, especificamente, que até então era pouco prioritário nas políticas públicas, passa a ganhar legitimidade ao se tornar um novo ator participativo sendo demandante de políticas, ações e estratégias específicas para esse segmento social (CASTRO, 2016b).

A maior visibilidade dos jovens rurais está associada a vários fatores, destacando-se: a criação de espaços juvenis no âmbito dos movimentos sociais e também a criação de redes e coletivos juvenis autônomos (CASTRO; BARCELOS, 2015); a constatação do envelhecimento

\footnotetext{
${ }^{5}$ Outros públicos contemplados na nova PNATER são pescadores, quilombolas, assentados da reforma agrária e povos tradicionais (BRASIL, 2004).
} 
e esvaziamento do campo $^{6}$; e o impacto desses dois processos para viabilidade e sustentabilidade das políticas de desenvolvimento rural (TROIAN, 2014).

Em virtude desses fatores, a inserção da juventude rural como público beneficiário das ações de ATER coloca alguns desafios principalmente ligados às demandas dos jovens quanto à educação, capacitação e atualização profissional e às oportunidades de autonomia econômica.

Dito isso, o objetivo deste artigo é analisar os mecanismos institucionais de ATER na aplicação das políticas públicas para os jovens na Zona da Mata Mineira, focalizando na análise o Projeto Transformar e a Semana da Juventude Rural.

\section{FUNDAMENTAÇÃO TEÓRICA}

\subsection{Políticas Públicas para a Juventude Rural Executadas pela ATER.}

As primeiras ações extensionistas dirigidas à juventude rural ocorreram entre as décadas de 1950 a 1980, denominados Clubes 4-S (saber, saúde, sentir e servir). Após serem desenvolvidos os projetos agrícolas individuais, os participantes tinham a chance de expor publicamente o resultado final da produção em vários eventos locais, realizados nos municípios por meio das Secretarias ligadas às Prefeituras. Os melhores colocados eram agraciados com bolsas de estudo, intercâmbios e máquinas agrícolas. Os jovens também participavam de eventos promovidos pelo Clube em outras localidades, como por exemplo, os congressos nos âmbitos estaduais e nacionais e eventos internacionais (SOUZA; OLIVEIRA; COELHO, 2016).

A política de crédito rural para o jovem já era implementada desde a década de 1950, cujo programa era conhecido como Crédito juvenil. Naquele contexto, o Estado Brasileiro elaborava projetos e políticas de modernização rural. Nesse caso, a juventude rural transformouse em debate público, que incluiu nas discussões temáticas representantes das organizações internacionais e do poder público, empresários, extensionistas rurais, docentes, lideranças comunitárias e, como ator social principal, os jovens rurais (MARIN, 2017).

Decorridos pelo tempo, as políticas públicas para juventude rural se tornaram restritivas por causa das dificuldades da agricultura familiar em acessar os créditos de financiamento rural e regularização fundiária. Para mudar o panorama social, o Governo Brasileiro instituiu no ano de 1998 o Programa Nacional de Educação e Reforma Agrária (PRONERA) cuja finalidade é promover uma política educacional aos jovens de assentamentos rurais. Em 2003, lançou mais dois programas: a versão do Programa Nacional de Fortalecimento da Agricultura Familiar para a juventude (PRONAF - Jovem) e a linha Nossa Primeira Terra no Programa Nacional de Crédito Fundiário (PNCF) (BARCELLOS, 2015).

No estudo realizado por Castro (2016a) destacou-se os avanços das políticas públicas no âmbito federal para a juventude rural, no qual a partir de 2005 as iniciativas de trabalho tornaram mais visíveis. Segundo a autora, outra contribuição das agendas foi a garantia de participação política dos representantes da juventude rural em conselhos federais, como o Conselho Nacional de Juventude e o Conselho Nacional de Desenvolvimento Rural Sustentável e da Agricultura Familiar, com objetivo de melhorar o diálogo entre atores políticos.

\footnotetext{
6 Os dados comparativos do Censo Agropecuário 2006-2017 (IBGE, 2019) constatam de que houve uma diminuição da taxa de participação dos jovens de até 25 anos de idade com variação de 3,3\% para 2,0\%. Nesse caso, a força de trabalho agrícola no campo está cada vez mais dependente em pessoas com faixas etárias mais avançadas, iniciando-se aos 45 anos. Em relação ao pessoal ocupado no campo, desde o Censo Agropecuário de 1985 que o pessoal ocupado no campo vem diminuindo a proporção influenciado principalmente no êxodo da juventude.
} 
Castro (2016a) ressalta, também, a instituição, no âmbito do então Ministério do Desenvolvimento Agrário, a elaboração do Plano Nacional de Juventude e Sucessão Rural ${ }^{7}$, promulgado em 2016, reiterando as múltiplas demandas envolvendo a permanência dos jovens na zona rural, assim como as principais diretrizes ${ }^{8}$ do Estado apresentadas no Plano. Complementando a informação, após as reivindicações dos movimentos sociais, o principal efeito positivo deste Plano é a formalização da educação do campo.

A publicação recente da Secretaria Nacional da Juventude (BRASIL, 2018) abordou algumas propostas destacadas nas ações estratégicas para atender ao público jovem tais como a reserva de $30 \%$ de novos lotes de terra para reforma agrária; quantidade de 50\% dos contratos celebrados para obtenção de créditos financeiros; acesso facilitado de mercados; ampliação de vagas do ensino técnico e superior; oferta dos serviços de telecomunicações, saúde e cultura; reserva de vagas nos Conselhos Participativos; entre outros.

No ponto de vista prático da realidade rural, Troian (2014) afirma em seu trabalho realizado em Arroio do Tigre (RS) que dos 18 jovens entrevistados apenas 3 conhecem as políticas públicas voltadas à produção agropecuária, como o Programa Nacional de Fortalecimento da Agricultura Familiar; e de acesso à terra, como o Programa Nacional de Crédito Fundiário. A autora aponta que há deficiências em relação à divulgação e ao acesso as políticas específicas para jovens, por não contemplarem outras áreas de atuação, como saúde e educação, onde a maioria deles (15) demonstram desconhecimento dessas políticas.

Ao analisar as políticas para a juventude rural, como o Pronaf Jovem, Barcellos (2017) argumenta que estas, com o planejamento feito, estão sujeitas a tensões, conflitos e negociações. Por isso, há divergências entre os resultados que o Estado espera da política pública e as expectativas profissionais dos jovens rurais, dos técnicos e dirigentes políticos que convivem em um determinado espaço rural.

\subsection{A EMATER-MG e suas Ações Institucionais para a Juventude Rural}

No contexto de suas atividades, atuante desde o ano 1948, a Empresa de Assistência Técnica e Extensão Rural do Estado de Minas Gerais (EMATER-MG) garantiu seu espaço institucional nas políticas públicas e tornou-se uma empresa pública referência na prestação de serviços de ATER com grande influência no meio rural mineiro. Com isso, a instituição obteve credibilidade com os agricultores familiares, principalmente depois da elaboração e operacionalização de várias políticas públicas voltadas a este segmento (COELHO, 2016). Para a Juventude Rural, a EMATER-MG tem se esforçado em desenvolver ações extensionistas com o intuito de que o jovem deseje continuar no meio rural.

Tanto é que a Empresa implementou dois programas de inserção participativa: o Projeto Transformar, atuante em todo território mineiro, desenvolvido de 2006 a 2013; e, especificamente na Região da Zona da Mata Mineira, a Semana da Juventude Rural, que iniciou em 2009 e está em execução até o presente momento.

O Projeto Transformar tem como seu cerne de trabalho a realização de cursos de qualificação de jovens rurais para que consigam aprimorar suas atividades produtivas. Esta

\footnotetext{
${ }^{7}$ Este Plano instituído tem como fator influenciador pelo Estatuto da Juventude, promulgado na Lei $\mathrm{n}^{\mathrm{o}} 12.852$, de 5 de agosto de 2013 (BRASIL, 2013). Nesta lei tem como principal princípio a emancipação social do jovem no respeito a participação política, bem-estar, autonomia financeira e educacional.

${ }^{8}$ Pelo Decreto N ${ }^{\circ}$ 8.736, de 3 de maio de 2016, as principais diretrizes deste Plano para os jovens rurais são as garantias sociais; acesso ao atendimento de qualidade em locais dos serviços públicos; promoção de políticas de desenvolvimento produtivo, sustentável e solidário; formação de conexões dos grupos da juventude em áreas rurais; promoção da identidade cultural; atuação transparente e democrática das suas atividades. Esta política pública diferenciada para a juventude rural tem como prioridade fazer parte da agricultura familiar além de estender também à comunidade quilombola e demais povos tradicionais (BRASIL, 2016).
} 
política pública visa favorecer o protagonismo dos jovens nos espaços rurais. Desde o ano da criação (2006) até 2011 o Programa qualificou 7.221 jovens com investimento próximo de um milhão e meio de reais (R\$ 1,5 milhão) aplicados em todo Estado de Minas Gerais (EMATERMG, 2011).

Através dessas atividades profissionalizantes promovidas pela EMATER-MG que o Projeto almeja o protagonismo da juventude rural fazendo com que os jovens tenham uma visão crítica além de prosperarem-se economicamente. Esta política pública busca promover uma melhor qualificação profissional dos jovens rurais no seu espaço territorial com uma melhor perspectiva social (SENA et al., 2010).

Outro evento sob responsabilidade da EMATER-MG corresponde a Semana da Juventude Rural em parceria com a Universidade Federal de Viçosa (UFV), onde começou em 2009. Acontece nas dependências da Universidade como parte da programação da Semana do Fazendeiro. Tem como propósito convidar os filhos dos agricultores familiares preferencialmente dos municípios da Região da Zona da Mata Mineira - a participarem do evento e promover a integração dos conhecimentos populares juntamente com os da Academia. Dessa maneira, propiciam aos jovens agricultores condições de terem maior contato com o ensino e tecnologia desenvolvidos nos laboratórios da Universidade (NEGRÃO; CABRAL, 2017).

Esta Semana constitui-se na reunião de jovens que são escolhidos pelos Sindicatos dos Trabalhadores Rurais (STRs) em seus respectivos municípios, em especial a Região da Zona da Mata Mineira. Nesse evento são abordadas variadas temáticas sociais como sexualidade, drogas e saúde, além de oficinas empreendedoras como a agroindústria e o artesanato. $\mathrm{O}$ objetivo desse evento é desenvolver atividades educativas permanentes e continuadas na formação cidadã do jovem (FUNDAÇÃO FACEV, 2016).

\section{METODOLOGIA}

A pesquisa aborda as atividades da EMATER-MG no Pólo Zona da Mata Mineira e a contribuição dos extensionistas rurais da Unidade Regional de Viçosa, onde a temática principal é a inclusão da juventude no desenvolvimento rural da região. Justifica-se neste escopo da pesquisa em nível regional pois à Região escolhida é considerada estratégica no desenvolvimento da agricultura familiar e por isso trará dimensionalidade da juventude rural. Lembra-se que este Pólo abrange 156 municípios.

Foram analisadas duas ações públicas em destaque: o Projeto Transformar, no período de 2006 a 2012, e a Semana da Juventude Rural, no período de 2009 a 2019. No desenvolvimento da pesquisa, faz-se a análise documental (RUAPP; BEUREN, 2006) sobre as duas atividades e entrevistas com extensionistas rurais da Unidade Regional da EMATER-MG de Viçosa.

Analisaram-se documentos fornecidos pela EMATER-MG Pólo Zona da Mata tanto do Projeto Transformar quanto da Semana da Juventude Rural: fichas de inscrições escaneadas, arquivos das planilhas e documentos digitalizados. Esses documentos contém os registros dos jovens, municípios residentes da Zona da Mata Mineira, número de projetos e oficinas, entre outras informações adicionais. Houve a necessidade de estimar as áreas temáticas dos cursos profissionalizantes atentando para questões de gênero dos participantes. Cederam-se através do envio de CDs os dados informativos provenientes da sede administrativa da EMATER-MG de Belo Horizonte.

Foram realizadas, também, entrevistas estruturadas, contendo perguntas fixas e simples possibilitando que o entrevistado seja direto e possa responder por escrito se assim desejar (GIL, 2008). Participaram dessas entrevistas três funcionários públicos da EMATER-MG, sendo uma

Revista Desenvolvimento Socioeconômico em debate v.7 n.1 (2021) 
coordenadora regional; um coordenador técnico e uma extensionista rural. Ocorreu a seleção dos entrevistados nesse processo durante a devido à disponibilidade dos entrevistados mediante ao contato realizado pelo pesquisador.

Nessas entrevistas foram elaboradas para respostas escritas manualmente no roteiro de 9 perguntas pertinentes ao Projeto Transformar; Semana da Juventude Rural e as atuações institucionais da Empresa na Unidade Regional da EMATER-MG de Viçosa (Quadro 1). Vale ressaltar que as respostas manuscritas dos entrevistados são sucintas em cada questão comentando de forma independente e individual mostrando o ponto de vista institucional com suas vivências de trabalho. Isso permite uma liberdade ao pesquisador de fazer suas interpretações em consonância com as respostas os servidores públicos.

Quadro 1 - Roteiro da entrevista aos funcionários públicos da UREGI-Viçosa

1 - O que você entende do Projeto Transformar? Na sua opinião, qual o principal propósito deste Projeto?

2 - O que entende da "Semana da Juventude Rural”? Na sua opinião, qual o principal propósito dessa Semana?

3 - Como a EMATER-MG ganhou importância para o desenvolvimento da juventude rural ?

4 - Na sua opinião, quais os resultados mais significativos que as políticas públicas para a juventude rural conseguiram alcançar na Unidade Regional de Viçosa?

5 - A EMATER-MG faz parcerias com outras organizações (sindicatos, associações, cooperativas, entre outros) para o fortalecimento da juventude rural da Região de Viçosa? Qual (is) foi (foram) a (s) mais significativa (s)?

6 - Quais as principais limitações da EMATER-MG na implementação de políticas públicas para a juventude rural da Região?

7 - A sustentabilidade no campo é abordada no Projeto Transformar e na Semana da Juventude Rural? Por quê?

8 - Quais cursos e/ou oficinas disponibilizados da EMATER-MG nos dois projetos os jovens demonstraram maior interesse?

9 - Você acredita que novas políticas públicas para a juventude rural serão desenvolvidas em parceria com a EMATER-MG? Cite algum (s) tipo (s) de política pública que na sua opinião seria interessante.

Elaborado pelos autores (2020).

\section{RESULTADOS E DISCUSSÕES}

\subsection{Projeto Transformar}

Em relação às metodologias de ATER para as políticas públicas da EMATER-MG, no Projeto Transformar, a instituição organizava os encontros nos municípios aptos a receberem o público jovem onde os extensionistas ministravam os cursos, visitas técnicas e dinâmicas de grupos.

No trabalho realizado por Castro (2016b), apontou algumas características dos jovens rurais do Sul de Minas Gerais em razão das análises das entrevistas dos integrantes do Projeto Transformar. Eles fazem parte da equipe de capacitação profissional desenvolvida pela EMATER-MG. Para gerar a autonomia produtiva, a autora argumenta que são necessárias ações que estimulem a juventude junto aos demais membros familiares, como: garantir a participação em eventos técnicos tais como cursos, oficinas, excursões, dias de campo, circuitos, entre outros; criar mecanismos de inserção dos jovens na comercialização de produtos nos programas governamentais e feiras livres.

A primeira informação (Quadro 2) refere-se ao número estimado de jovens participantes nos cursos de capacitação nas Unidades Regionais (UREGIs). Registrou-se, de 2007 a 2012, que 709 jovens participaram das oficinas. Destacam-se quantitativamente pelo menos três regionais da EMATER-MG: Muriaé, Cataguases e Juiz de Fora com a participação de 267, 134 e 108 jovens, respectivamente. No entanto, houve pequenas modificações nos anos decorridos 
do Projeto tanto na soma geral quanto nas médias. Entretanto, no ano de 2012 reduziram-se drasticamente os cursos de capacitação em razão da iminência do término dessa política pública.

Estimou-se, também no mesmo Quadro, a participação feminina no Projeto. Com exceção da UREGI de Ponte Nova, a média geral da taxa estimada no Pólo Zona da Mata é de $29 \%$, sendo que a UREGI Manhuaçu destoa em relação à média. Os dados não são precisos em razão da falta dos registros nominais.

Segundo a extensionista da EMATER na UREGI-Viçosa, pela sua vivência de trabalho na região, ao menos dois fatores contribuíram para este índice: a questão cultural e produtiva. A primeira é justificada pela resistência dos pais em permitirem seus filhos, os jovens selecionados, a dormirem fora de casa, uma vez que os cursos foram realizados em escolas e universidades. A outra, segundo a entrevistada, consiste no fato de que o homem, de modo geral, tem uma participação mais efetiva nas atividades.

Quadro 2 - Número Total Estimado e a Média dos Jovens Participantes nos Cursos de Capacitação do Projeto Transformar nas Unidades Regionais (UREGIs) da EMATER - MG, de 2007 a 2012.

\begin{tabular}{|c|c|c|c|c|c|c|c|c|}
\hline \multirow{2}{*}{$\begin{array}{c}\text { Unidade } \\
\text { Regional } \\
\text { (UREGI) }\end{array}$} & $\mathbf{2 0 0 7}$ & $\mathbf{2 0 0 8}$ & $\mathbf{2 0 0 9}$ & $\mathbf{2 0 1 0}$ & $\mathbf{2 0 1 1}$ & $\mathbf{2 0 1 2}$ & Total & $\begin{array}{c}\text { Taxticipação Feminina em } \\
\text { Pardia de } \\
\text { cada UREGI (\%) }\end{array}$ \\
\hline Cataguases & 52 & - & $49^{9}$ & - & 30 & $3^{9}$ & $\mathbf{1 3 4}$ & $\mathbf{2 5}$ \\
\hline Juiz de Fora & 42 & - & - & - & $41^{9}$ & 25 & $\mathbf{1 0 8}$ & $\mathbf{1 7}$ \\
\hline Manhuaçu & - & - & $16^{9}$ & 50 & - & - & $\mathbf{6 6}$ & $\mathbf{5 6}$ \\
\hline Muriaé & 42 & $73^{9}$ & 101 & - & $48^{9}$ & - & $\mathbf{2 6 4}$ & $\mathbf{2 4}$ \\
\hline Ponte Nova $^{10}$ & - & - & - & 50 & - & - & $\mathbf{5 0}$ & $\mathbf{2 4}$ \\
\hline Viçosa & $37^{9}$ & - & - & 50 & - & - & $\mathbf{8 7}$ & $\mathbf{2 4}$ \\
\hline Total & $\mathbf{1 7 3}$ & $\mathbf{7 3}$ & $\mathbf{1 6 6}$ & $\mathbf{1 5 0}$ & $\mathbf{1 1 9}$ & $\mathbf{2 8}$ & $\mathbf{7 0 9 1 1}$ & Média Geral $=\mathbf{2 9 \%}$ \\
\hline
\end{tabular}

Fonte: EMATER-MG, elaborados pelos autores - 2020.

Os cursos de capacitação fazem parte do processo de educação não formal do Projeto Transformar. Os jovens realizam diversas atividades com destaque para a pecuária; agroecologia; associativismo; agroindústria; entre outros, alternando o conhecimento teórico e prático no próprio espaço rural. Esse processo tem como finalidade a formação profissional e cidadã dos jovens, filhos e filhas de agricultores familiares, aperfeiçoando suas capacidades profissionais e criando alternativas que podem resultar em ocupação e renda. Com isso, após o cumprimento dos cursos, permite-se ao jovem o acesso do crédito rural do PRONAF (SENA et al., 2010).

Na sequência, houve a seleção dos jovens residentes dos municípios do Pólo Zona da Mata a realizarem suas atividades. Os resultados do Quadro 3 apresentam os municípios contemplados, cursos e/ou palestras ministrados no período de 2007 a 2012. Observa-se um total de 84 municípios em todo o Pólo da Zona da Mata e 90 cursos e/ou palestras ministrados em diversas áreas no âmbito agropecuário, extensionista, político-econômico e social.

Quadro 3 - Relação dos Municípios Atendidos no Pólo Zona da Mata Mineira e os Cursos Ministrados no Projeto Transformar, de 2007 a 2012.

\begin{tabular}{|c|c|c|}
\hline UREGI & Municípios Atendidos pelos Jovens Representantes & $\begin{array}{c}\text { Cursos e/ou Palestras } \\
\text { Ministrados }\end{array}$ \\
\hline Cataguases & 23 & 15 \\
\hline Juiz de Fora & 22 & 24 \\
\hline
\end{tabular}

\footnotetext{
${ }^{9}$ Valores condicionais para estimação da taxa de participação feminina;

${ }^{10}$ Não foi estimada a taxa de participação feminina.

${ }^{11}$ Este resultado estimado não apresenta repetição dos jovens cursandos.
} 


\begin{tabular}{|c|c|c|}
\hline Manhuaçu & 3 & 25 \\
\hline Muriaé & 22 & 19 \\
\hline Ponte Nova & 1 & 3 \\
\hline Viçosa & 13 & 4 \\
\hline Total & $\mathbf{8 4}$ & $\mathbf{9 0}$ \\
\hline
\end{tabular}

Fonte: EMATER-MG, elaborados pelos autores - 2020.

Como supracitado, os jovens realizavam seus respectivos cursos para obtenção dos créditos do PRONAF Jovem no período de 2006 a 2013. Dito isso, os dados a seguir analisados mostram que algumas cidades do Pólo da Zona da Mata Mineira foram contempladas com as aprovações dos projetos agropecuários pelos bancos públicos. No entanto, os dados não especificaram as áreas destinadas dos investimentos nos projetos tornando-se um fator limitante para futuras abordagens.

Como pode-se observar no Quadro 4, dos 71 projetos aprovados no Pólo, destacaramse as cidades de Ipanema com 9 projetos; seguido por Santa Rita de Jacutinga, com 8; Cataguases, com 7; Mar de Espanha e Santa Bárbara do Monte Verde, com 5 projetos cada. Esses municípios também tiveram suas maiores verbas para investimentos possuindo $47 \%$ dos R\$ 462.760,26 aplicados nas 27 cidades selecionadas. Uma situação contrastante é que o número de projetos corresponde a $10 \%$ do público jovem atendido no Projeto Transformar. Assim é perceptível que o orçamento limitado dos investimentos para execução de projetos agropecuários para a juventude rural é latente.

Quadro 4 - Projetos e Investimentos no Pólo Zona da Mata Mineira (2006 a 2013)

\begin{tabular}{|c|c|c|c|c|c|}
\hline Município & $\begin{array}{c}\mathbf{N}^{\circ} \text { de } \\
\text { Projetos }\end{array}$ & $\begin{array}{c}\text { UREGI da } \\
\text { EMATER-MG }\end{array}$ & Município & $\begin{array}{c}\text { UREGI da } \\
\text { EMATER- } \\
\text { MG } \\
\end{array}$ & $\begin{array}{c}\text { Investimentos } \\
\text { (R\$) }\end{array}$ \\
\hline Ipanema & 9 & Manhuaçu & Ipanema & Manhuaçu & $54.000,00$ \\
\hline $\begin{array}{l}\text { Santa Rita De } \\
\text { Jacutinga }\end{array}$ & 8 & Juiz de Fora & $\begin{array}{l}\text { Santa Rita de } \\
\text { Jacutinga }\end{array}$ & Juiz de Fora & $50.903,47$ \\
\hline Cataguases & 7 & Cataguases & Cataguases & Cataguases & $50,475,24$ \\
\hline Mar de Espanha & 5 & Cataguases & Mar de Espanha & Cataguases & $33.000,00$ \\
\hline $\begin{array}{l}\text { Santa Barbara do } \\
\text { Monte Verde }\end{array}$ & 5 & Juiz de Fora & $\begin{array}{l}\text { Santa Barbara do } \\
\text { Monte Verde }\end{array}$ & Juiz de Fora & $30.000,00$ \\
\hline Silveirânia & 4 & Cataguases & Silveirânia & Cataguases & $24.000,00$ \\
\hline Oliveira Fortes & 3 & Juiz de Fora & $\begin{array}{l}\text { Santana de } \\
\text { Cataguases }\end{array}$ & Cataguases & $20.000,00$ \\
\hline Rio Novo & 3 & Cataguases & Oliveira Fortes & Juiz de Fora & $18.000,00$ \\
\hline $\begin{array}{l}\text { Santana de } \\
\text { Cataguases }\end{array}$ & 3 & Cataguases & Rio Novo & Cataguases & $18.000,00$ \\
\hline Aracitaba & 2 & Juiz de Fora & Dom Silvério & Ponte Nova & $15.000,00$ \\
\hline Leopoldina & 2 & Muriaé & Tabuleiro & Cataguases & $15.000,00$ \\
\hline Lima Duarte & 2 & Juiz de Fora & Manhuaçu & Manhuaçu & $13.000,00$ \\
\hline Manhuaçu & 2 & Manhuaçu & Aracitaba & Juiz de Fora & $12.000,00$ \\
\hline Paiva & 2 & Juiz de Fora & Paiva & Juiz de Fora & $12.000,00$ \\
\hline Senador Cortes & 2 & Cataguases & Senador Cortes & Cataguases & $12.000,00$ \\
\hline Belmiro Braga & 1 & Juiz de Fora & Lima Duarte & Juiz de Fora & $11.997,30$ \\
\hline Cipotânea & 1 & Viçosa & Leopoldina & Muriaé & $11.155,60$ \\
\hline Descoberto & 1 & Cataguases & Cipotânea & Viçosa & $7.000,00$ \\
\hline Dom Silvério & 1 & Ponte Nova & Guarará & Cataguases & $7.000,00$ \\
\hline Guarará & 1 & Cataguases & Lajinha & Manhuaçu & $6.230,00$ \\
\hline Lajinha & 1 & Manhuaçu & Belmiro Braga & Juiz de Fora & $6.000,00$ \\
\hline Miraí & 1 & Cataguases & Descoberto & Cataguases & $6.000,00$ \\
\hline Muriaé & 1 & Muriaé & Miraí & Cataguases & $6.000,00$ \\
\hline Mutum & 1 & Manhuaçu & Muriaé & Muriaé & $6.000,00$ \\
\hline Olaria & 1 & Cataguases & Mutum & Manhuaçu & $6.000,00$ \\
\hline
\end{tabular}




\begin{tabular}{|c|c|c|c|c|c|}
\hline Passa Vinte & 1 & Juiz de Fora & Passa Vinte & Juiz de Fora & $6.000,00$ \\
\hline Tabuleiro & 1 & Cataguases & Olaria & Juiz de Fora & $5.998,65$ \\
\hline $\begin{array}{c}\mathbf{N}^{\mathbf{o}} \text { Total de } \\
\text { Projetos }\end{array}$ & $\mathbf{7 1}$ & - & $\begin{array}{c}\text { Valor Total de } \\
\text { Investimentos } \\
(\mathbf{R} \$)\end{array}$ & - & $\mathbf{4 6 2 . 7 6 0 , 2 6}$ \\
\hline
\end{tabular}

Fonte: EMATER-MG, elaborados pelos autores - 2020.

Dessa forma, todas as UREGIs da EMATER-MG do Pólo da Zona da Mata puderam acompanhar o planejamento dos projetos agropecuários idealizados pelos jovens produtores rurais. A equipe de extensionistas rurais da UREGI de Cataguases foi a que mais deu assistência e direcionamento para que os jovens conseguissem acesso ao crédito de financiamento rural, onde acompanharam 29 projetos em 11 municípios.

Tanto as organizações sociais quanto as políticas juvenis dão condições sociais que sinalizam os rumos necessários na qualificação dos jovens para no futuro firmar profissionalmente na idade adulta. O exemplo aplicado do PRONAF Jovem prevê a conversação de uma série de instituições ligados ao desenvolvimento rural simultaneamente em que impulsiona uma ideação das atribuições da juventude rural na sociedade (MARIN, 2020).

Nesse sentido, o PRONAF Jovem significa a compatibilidade dos investimentos sociais demonstrando o esforço institucional para juventude rural. Esta política de desenvolvimento também simboliza um empenho exercido nas expectativas criadas que conformam um padrão do jovem ser como sucessor natural da agricultura familiar pela conjugação de acessos aos créditos bancários, aos serviços e à qualificação profissional, no qual possibilitam melhores oportunidades de se manter ativo no campo. Em tais condições, objetiva-se que os jovens qualificados ingressem na fase adulta já adaptados ao modelo de agricultura familiar (MARIN, 2020).

Cabe ressaltar a relevância do PRONAF como um instrumento de grande importância para o desenvolvimento rural, que possibilita o fortalecimento da agricultura familiar, como meio de assegurar a permanência do jovem seja no trabalho da propriedade rural seja na sucessão familiar. Ademais, apesar das comunidades serem menos assistidas pelo poder municipal, observa-se a presença de políticas públicas federais sendo amplamente abordadas e como forma de manutenção do jovem no espaço rural. Dentre essas, destaca-se a maior dimensão do PRONAF Jovem, atuando, por meio de projetos, no empreendedorismo do jovem e no seu poder de decisão (BASTOS et al., 2015).

\subsection{Semana da Juventude Rural}

Para o desenvolvimento da Semana da Juventude Rural, a EMATER-MG estabeleceu uma parceria com a UFV e, nesse trabalho em conjunto, tiveram condições de organizar a seleção dos mini-cursos e contatar preferencialmente os Escritórios Locais do Pólo Zona da Mata Mineira na seleção dos jovens representantes. A diferença fundamental em relação ao Projeto Transformar se dá pelo suporte logístico e a estrutura da Universidade. Os selecionados na Semana da Juventude devem participar das oficinas (ou minicursos), que por sua vez propiciam os jovens a terem contato e se familiarizarem com as novas tecnologias e saberes para levar expansão do conhecimento.

Os dados analisados sobre a Semana da Juventude Rural, (Quadro 5), mostram que houve uma frequente oscilação na demanda dos jovens participantes no evento, entre 2009 e 2019. O ápice foi no ano de 2013, onde 245 pessoas prestigiaram-na. Em relação aos municípios do Pólo da Zona da Mata Mineira, a adesão dos Escritórios Locais foi crescente de 2010 a 2013 (com adesão recorde de 93 municípios). Alguns destes municípios, em todas as edições, se 
empenharam em mobilizar os jovens a participarem do evento, como Simonésia, com 101 participantes; Rosário da Limeira, 86; Acaiaca, 48 e Paula Cândido, 46.

Contudo, de maneira geral, houve uma queda acentuada tanto na participação da juventude quanto na abrangência dos municípios nas VI e VII Semanas. Nas $8^{\mathrm{a}}, 9^{\mathrm{a}}$ e $11^{\mathrm{a}}$ edições, volta a crescer o número de participantes, nos 11 anos do período analisado, participaram nas atividades promovidas pela EMATER-MG/UFV 1.824 jovens.

Em se tratando de gênero, a média da taxa de participação feminina nas Semanas realizadas é de $33 \%$, sendo que a $4^{\mathrm{a}}$ e a $5^{\mathrm{a}}$ Semana tiveram baixíssima adesão. Enquanto na $2^{\mathrm{a}}$, $3^{\mathrm{a}}, 6^{\mathrm{a}}, 7^{\mathrm{a}}, 8^{\mathrm{a}}, 9^{\mathrm{a}}, 10^{\mathrm{a}}$ e $11^{\mathrm{a}}$ Semana tiveram índices ligeiramente menores que a masculina. $\mathrm{O}$ fator cultural e o produtivo são as principais causas plausíveis para o valor mensurado da taxa média de participação feminina.

Quadro 5 - Análise dos Dados da Semana da Juventude Rural de 2009 a 2019.

\begin{tabular}{|c|c|c|c|c|c|}
\hline Semana & Participantes & Mulheres & $\begin{array}{c}\text { Taxa de Participação } \\
\text { Feminina (\%) }\end{array}$ & $\begin{array}{c}\text { Abrangência dos } \\
\text { Municípios }\end{array}$ & Oficinas \\
\hline I (2009) & - & - & - & - & 15 \\
\hline II (2010) & 200 & 65 & 32 & 60 & 15 \\
\hline III (2011) & 150 & 52 & 35 & 80 & 13 \\
\hline IV (2012) & 171 & 30 & 18 & 93 & 12 \\
\hline V (2013) & 245 & 47 & 19 & 48 & 9 \\
\hline VI (2014) & 186 & 58 & 31 & 36 & 12 \\
\hline VII (2015) & 140 & 61 & 44 & 52 & 11 \\
\hline VIII (2016) & 178 & 64 & 36 & 63 & 13 \\
\hline IX (2017) & 197 & 71 & 36 & 52 & 18 \\
\hline X (2018) & 165 & 66 & 40 & 45 & - \\
\hline XI (2019) & 192 & 71 & 37 & $\mathbf{5 9}$ & 147 \\
\hline Total & 1.824 & 585 & $\mathbf{3 3}$ & & $\mathbf{1 3}$ \\
\hline Média & $\mathbf{1 8 2}$ & $\mathbf{5 9}$ & & & \\
\hline
\end{tabular}

Fonte: EMATER-MG/UFV, elaborados pelos autores - 2020

Dos Escritórios Locais da EMATER-MG mais representativos, Simonésia, Rosário da Limeira e Acaiaca, apresentaram taxas de participação feminina superiores à média na Semana da Juventude Rural nos valores de 40\%; 48\% e 50\%, respectivamente. Destacam-se importantes considerações na participação feminina nesses Escritórios segundo informações dos extensionistas.

No caso do Escritório em Rosário da Limeira, a EMATER-MG fez parceria entre a Prefeitura e o Sindicato dos Trabalhadores Rurais para selecionar os jovens a participarem no Evento. Outro fator que pode ter feito oscilar as participações masculinas e femininas no Evento é a colheita do café, porque o mês do evento (geralmente em julho) coincide com esta atividade que necessita de mão-de-obra.

Nos Escritórios de Simonésia e Acaiaca, a EMATER-MG tem trabalhado em conjunto com as Escolas Famílias Agrícolas nesses municípios para motivar o interesse das jovens em continuar na atividade rural. Nessas escolas, as mulheres têm menor taxa de evasão e com isso há uma ampliação no aprimoramento dos conhecimentos através dos cursos oferecidos neste evento.

Em relação às oficinas, são ministradas com o intuito de proporcionar ao jovem rural o contato com outras tecnologias levando sempre em consideração a aplicabilidade desses conhecimentos no campo. Isso desperta a curiosidade do jovem participante na possibilidade de aplicar os conhecimentos adquiridos durante o evento. Elas são ministradas tanto pelos extensionistas rurais da EMATER-MG quanto pelos pesquisadores e técnicos da UFV.

Esta elaboração é definida, segundo a coordenadora regional da EMATER-MG, no consenso dos técnicos da própria empresa e a UFV. Escolhem-se os cursos a partir da Semana 
da Juventude Rural do ano anterior aliada ao tema que está em pauta no corrente ano na Semana do Fazendeiro. Assim, é construída a proposta das oficinas e palestras de acordo com as demandas e potencialidades da juventude rural em áreas de produção, comercialização e gestão de pessoas.

Os minicursos são selecionados e distribuídos nas mais variadas temáticas. Ao longo das edições do evento realizaram-se 147 oficinas acumuladas. São alguns exemplos já empregadas: Agroecologia; Associativismo/Cooperatvismo; Cafeicultura; Drogas e Doenças Sexualmente Transmissíveis (DSTs); Educação Ambiental; Energia Renovável; Fabricação de Tijolos; Geoprocessamento; Juventude Rural; Saneamento Rural; Tinta de Solo; Troca de Saberes e outros.

Por meio do Gráfico 1, pode-se observar os dados das áreas temáticas por onde são inseridas as oficinas. A Engenharia Agrícola destaca-se entre as áreas selecionadas, com $24 \%$. Em seguida, tem a Construção Civil, com 20\%; Fitotecnia, com 17\%; Extensão Rural, com 11\%; Meio Ambiente, Serviço Social e Saúde, com 7\% cada; Produção Animal, com 4\%; e Economia Rural, com 3\%. Isso respalda o propósito da EMATER - MG em diversificar as atividades extensionistas demostradas no evento ao estabelecer suas oficinas.

Gráfico 1 - Distribuição das Áreas Temáticas nas Oficinas Ministradas pela Semana da Juventude Rural de 2009 a 2019.

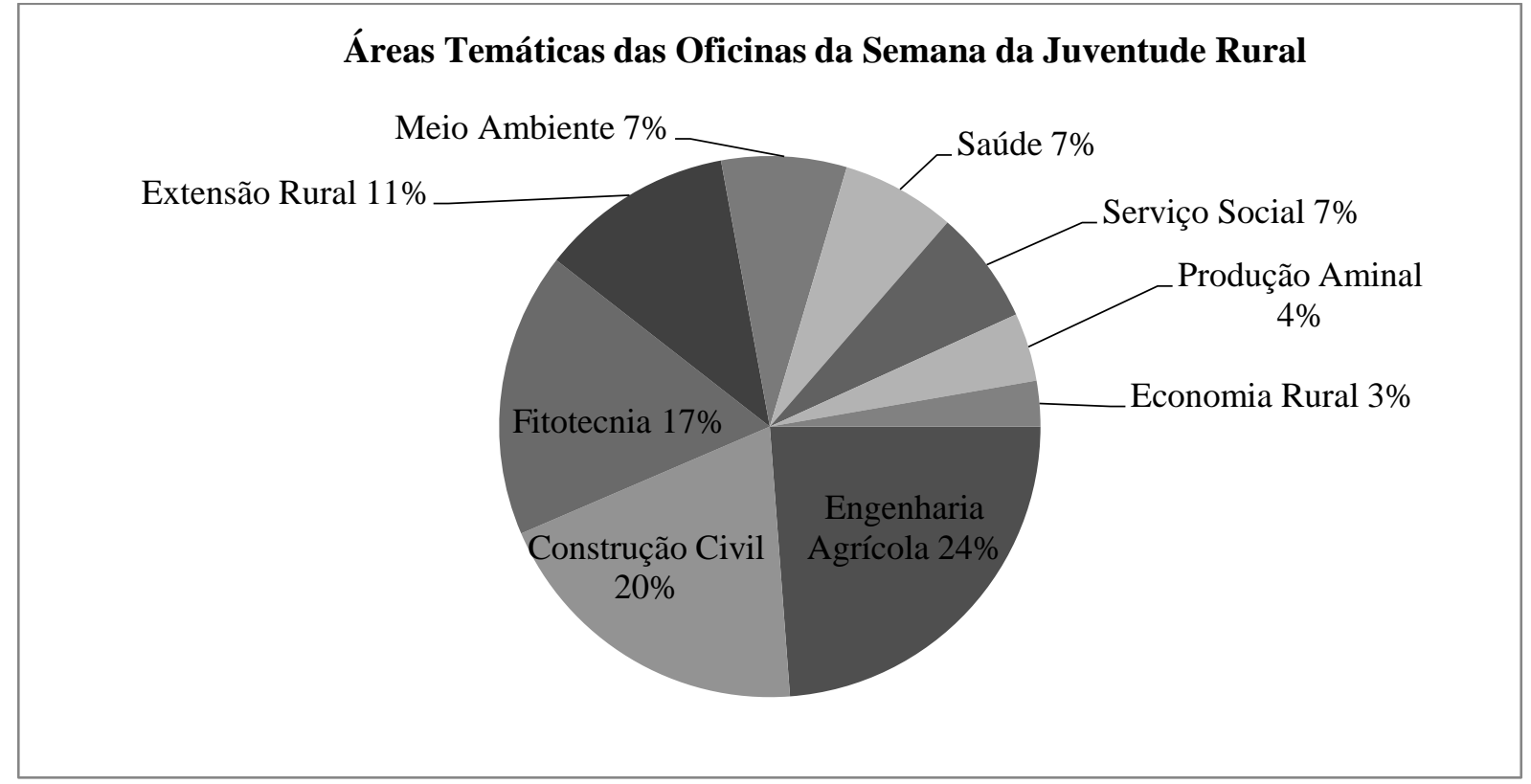

Fonte: EMATER-MG/UFV, elaborados pelos autores - 2020.

Os resultados mostrados acima reforçam a importância da aplicação das políticas públicas para os jovens no aprimoramento das oficinas ministradas simultaneamente no Evento. Em uma pesquisa desenvolvida na $5^{\text {a }}$ Semana da Juventude pela Souza, Doula e Carmo (2017) diz que a maioria dos jovens entrevistados afirmou que realizava mais de uma atividade nos cuidados da agricultura, pecuária, serviços domésticos e sazonais tanto na própria propriedade familiar quanto nas circunvizinhanças.

Conforme Staloch e Rocha (2018), após o desenvolvimento de projeto participativo com os jovens nas propriedades rurais, houve maior sensibilização aos jovens e a partir daí tiveram uma ampla visão para que o estabelecimento tornasse cada vez mais produtivo. Neste modelo, os jovens descobriram que o cultivo agroecológico, o artesanato local e o agroturismo são atividades que possibilitariam uma grande chance de sucesso na sua própria permanência no campo. 


\subsection{Considerações dos Extensionistas Rurais da EMATER-MG Entrevistados}

Ao serem questionados sobre o Projeto Transformar, os entrevistados alegaram que esta política pública foi importante para a formação cidadã dos jovens. Segundo a coordenadora e a extensionista, os jovens desenvolvem atividades produtivas de profissionalização para a geração de renda. O coordenador ressaltou também que o Projeto abordava aspectos relativos ao empreendedorismo dos jovens rurais a fim de que após a formação técnica tivessem condições de acessar as linhas de crédito no banco.

Com relação a Semana da Juventude Rural, tanto a coordenadora quanto a extensionista afirmam que o objetivo da Semana é proporcionar um espaço de discussão, troca de experiências e aprender as tecnologias de produção agrícola e gestão rural. Sobre a parceria entre a EMATER-MG e UFV para o desenvolvimento da Semana, o coordenador afirmou que a EMATER estabeleceu a parceria com a UFV no intuito de discutir as questões da sucessão familiar e qualidade de vida no meio rural.

Nesta entrevista, duas questões foram correlacionadas às duas políticas públicas da EMATER-MG sendo uma sobre a sustentabilidade e outro referente aos cursos mais pedidos pelos jovens. No que se refere à sustentabilidade, os entrevistados consideraram ser um tema de grande relevância. Além disso argumentam que por meio das questões que norteiam o tema foi possível trabalhar eixos como o desenvolvimento econômico, social, ambiental e organizacional e o coordenador ressaltou o uso das energias alternativas e do uso de matériasprimas locais para a bioconstrução.

Nas oficinas feitas nos dois projetos, afirmam que os jovens têm preferências pela Agroecologia; Agroindústria; Bovinocultura de Leite; Cafeicultura; Comercialização e Gestão; Energias Alternativas; Horticultura; Olericultura; Planejamento da Habitação Rural; Produção Agrícola; e Aspectos Relacionados à Saúde.

Sobre a importância institucional da EMATER-MG para a juventude rural, os técnicos expuseram as contribuições deste órgão público no desenvolvimento rural para o público jovem. Tanto para o coordenador quanto para a extensionista, sua importância centra-se na elaboração de ações visando o bem-estar profissional do jovem e a promoção da autonomia financeira através das atividades de Extensão Rural. Já a coordenadora destacou os principais programas implantados pela EMATER-MG: o Programa Projeto 4S - Saber, Sentir, Saída e Servir, comentado por Souza, Oliveira e Coelho (2016); em 1983, Política de Juventude; Projeto Transformar em 2006 - Uma Nova Minas com a Juventude Rural; e em 2009, Semana da Juventude Rural Zona da Mata.

Os técnicos citaram também outras ações de políticas públicas interessantes onde a Empresa Pública pôde trabalhar em parceria tais como acesso dos produtores ao crédito rural; Escolas rurais oferecendo ensino de qualidade; Valorização das atividades agrícolas e não agrícolas; e Serviços sociais.

Sobre os resultados mais significativos que as políticas públicas alcançaram para a juventude rural na região de Viçosa, a extensionista e a coordenadora afirmaram que a inserção dessas políticas específicas para agricultura familiar e adoção de tecnologias nas propriedades rurais tiveram destaques. Enquanto o coordenador considerou que a maior contribuição da EMATER-MG para a região foi à permanência do jovem no campo na sucessão familiar.

Os técnicos também citaram algumas instituições que firmaram importantes parcerias com a EMATER-MG para a juventude rural na Região tais como a UFV, Prefeituras e Câmaras Municipais; Associação de Agricultores Familiares; Sindicatos de Trabalhadores Rurais; Conselho Municipal de Desenvolvimento Rural Sustentável; Federação dos Trabalhadores na 
Agricultura do Estado de Minas Gerais (FETAEMG) e Empresas de Tecnologia para ministração dos cursos ${ }^{12}$.

Uma pergunta destacada das políticas de Estado para o desenvolvimento rural são as limitações estruturais de trabalho da Instituição. Os entrevistados apontaram algumas delas. A coordenadora e a extensionista responderam os três fatores limitantes que dificultam o trabalho de implementação com os jovens como falta de recursos para os projetos de financiamento, falta de apoio dos pais para conseguir a sua independência e falta do acesso à terra. Outro extensionista rural comentou que a quantidade elevada dos municípios mineiros, maior incidência dos jovens (que acessam essas políticas) na faixa dos 30 anos e a limitação de transporte e hospedagem ampliam a dificuldade de se desenvolver a atividade extensionista.

Guimarães (2009) pontua três considerações no planejamento participativo das atividades da Extensão Rural na UREGI-Viçosa, no qual podem auxiliar nas políticas públicas de apoio ao desenvolvimento da juventude rural: mudança de atitudes institucionais necessárias para organizar os processos; compartilhar suas experiências de trabalho priorizando as organizações coletivas; e a necessidade do extensionista rural de ter uma visão crítica no processo de interferência técnica e dialógica.

Castro e Pereira (2017) afirmam que a política de comunicação institucional da EMATER-MG foi reestruturada, transferindo o modelo rígido de trabalho para integral e horizontal. Isso facilitou a flexibilização da ação extensionista no amparo aos agricultores familiares e organizações para acesso às políticas públicas no âmbito agrícola ${ }^{13}$. Os principais feitos, destacam-se a formação de uma rede de divulgação de informações; e a construção de responsabilidades técnicas a respeito do mercado agropecuário e institucional, tornando o trabalho mais qualificado e menos custoso.

De fato, segundo Coelho (2016), as atividades realizadas pela UREGI-Viçosa não mais priorizam a orientação produtivista no seu modelo atual de gestão de ATER. Entretanto, mesmo com as transformações ocorridas nos conceitos de Extensão Rural além nas novas orientações metodológicas exigidas, ainda é insuficiente a multidisciplinaridade da Unidade em relação ao quadro de profissionais, predominantemente dominado pelas ciências agrárias.

\section{CONSIDERAÇÕES FINAIS}

Os dados analisados evidenciam a importância da execução das políticas públicas para a juventude rural, bem como a relevância da instituição pública de ATER, neste caso a EMATER-MG. Afinal, mesmo com as limitações estruturais na condução dos trabalhos, a instituição consegue cativar o público jovem a participar dos cursos oferecidos nos dois Projetos.

No Projeto Transformar para o Pólo Zona da Mata, houve esforços da EMATER-MG para incentivar o jovem a participar dos cursos de capacitação em várias Regionais. Apesar dos dados incompletos, esta política pública atendeu a maioria dos municípios da Zona da Mata, com destaque nas UREGIs de Muriaé, Cataguazes e Juiz de Fora além de 90 cursos ministrados. No caso de atendimento aos jovens participantes a demanda atendida no Pólo corresponde na faixa de $10 \%$ do público em relação ao todo território mineiro segundo informações da EMATER-MG (2011). Entretanto, o baixo orçamento para liberação dos projetos aprovados no PRONAF Jovem limitou ainda mais o acesso de crédito aos jovens rurais na Região.

\footnotetext{
12 Dois últimos itens respondidos pelo coordenador técnico.

${ }^{13}$ Nesse artigo foi mencionado como exemplos de aplicação a Política de Aquisição de Alimentos (PAA) e Programa Nacional de Alimentação Escolar (PNAE). Porém, serve de base para outras políticas públicas para facilitar a atuação dos extensionistas da EMATER-MG.
} 
Com a parceria entre a EMATER-MG e a UFV, a participação dos jovens na Semana da Juventude Rural teve relevância superior do que no Projeto Transformar por causa da logística, maior espaço da Universidade e a vasta distribuição das oficinas em diferentes áreas temáticas, no qual as mais selecionadas nas onze edições foram Engenharia Agrícola, Construção Civil e Fitotecnia. Prioritariamente, selecionaram-se os jovens de vários municípios da Zona da Mata Mineira onde a instituição é responsável. As principais limitações desse evento são a carga horária reduzida e a falta da demanda necessária para as oficinas e a consideração das políticas de gênero, onde a taxa de participação feminina é considerada baixa.

Em relação ao corpo técnico, os profissionais da EMATER-MG do Escritório de Viçosa enfatizaram seus pontos de vista com os trabalhos da Extensão Rural nos dois eventos e a importância institucional para a juventude rural. Para o Projeto Transformar e a Semana da Juventude Rural, os servidores explanaram os pontos fortes das duas políticas, sobretudo, através dos cursos ministrados, para que os jovens alcancem sua autonomia. Além disso, eles enfatizaram as valorosas parcerias da EMATER-MG com outras instituições; a discussão da sustentabilidade; as finalidades dos cursos; as limitações e as atividades das políticas públicas da juventude tendo foco principal o desenvolvimento rural.

No caso da instituição, os servidores afirmam que a Empresa Pública possui a responsabilidade de executar suas atividades para a política de juventude rural. E para cumprir as suas diretrizes, organiza os cursos de capacitação; assistência técnica; cria alternativas na melhoria do serviço de Extensão Rural; promover articulações com outras instituições, entre outros.

Com isso, vale destacar, através dos dados levantados nas duas políticas públicas, que o desenvolvimento da juventude rural na Região da Zona da Mata Mineira apresenta limitações que devem estar atentos aos trabalhos futuros da Extensão Rural principalmente no que tange ao orçamento público reduzido que limita o acesso profissionalizante e a participação relativamente menor das mulheres jovens. Mesmo assim, a EMATER-MG vem cumprindo dentro das possibilidades o seu papel extensionista.

\section{REFERÊNCIAS}

BARCELLOS, S. B. A formulação das políticas públicas para a juventude rural no Brasil e os elementos constitutivos desse processo social. Mundo Agrário, La Plata, v.16, n.32, 2015.

BARCELlOS, S. B. As Políticas Públicas Para A Juventude Rural: o Pronaf jovem em debate. Planejamento e Políticas Públicas, n. 48, p. 149-173, jan.jun./2017.

BASTOS, L. C.; EMMENDOERFER, M. L.; SILVEIRA, S. de F. R.; GOMES, A. L. Queremos Ficar no Meio Rural, Mas Como? Tecnologias de Administração e

Contabilidade. Rio de Janeiro, vol. 5, n. 2, pp. 147-164, Jul./Dez. 2015.

BRASIL. Política Nacional de Assistência Técnica e Extensão Rural. Brasília: Ministério do Desenvolvimento Agrário. 2004. 22 p.

BRASIL. Lei $\mathbf{N}^{\mathbf{0}}$ 12.852, de 5 de agosto de 2013. Institui o Estatuto da Juventude e dispõe sobre os direitos dos jovens, os princípios e diretrizes das políticas públicas de juventude e o Sistema Nacional de Juventude - SINAJUVE. Brasília: Presidência da República. 2013. Disponível em: http://www.planalto.gov.br/ccivil_03/_Ato2011-2014/2013/Lei/L12852.htm> Acesso no dia 27/07/2020. 
BRASIL. Decreto $\mathbf{N}^{\mathbf{0}}$ 8.736, de 3 de maio de 2016. Institui o Plano Nacional de Juventude e Sucessão Rural. Brasília: Presidência da República. 2016. Disponível em: http://www.planalto.gov.br/CCIVIL_03/_Ato2015-2018/2016/Decreto/D8736.htm> Acesso no dia 27/07/2020.

BRASIL. Diagnóstico situacional e diretrizes para políticas públicas para as juventudes rurais brasileiras. Brasília: Secretaria Nacional da Juventude. 2018. 145 p.

CASTRO, C. N. de; PEREIRA, C. N.; Agricultura Familiar, Assistência Técnica e Extensão Rural e a Política Nacional de ATER. Texto para Discussão, Rio de Janeiro, n. 2343, 48 p., out. 2017.

CASTRO, E. G. de. Juventude Rural, do Campo, das Águas e das Florestas: a primeira geração jovem dos movimentos sociais no Brasil e sua incidência nas políticas públicas de juventude. Política \& Trabalho: Revista de Ciências Sociais, João Pessoa, n. 45, Julho/Dezembro de 2016a, p. 193-212.

CASTRO, F. A. T. Juventude rural e as contribuições do Projeto Transformar de capacitação de jovens rurais no Sul de Minas Gerais (2006-2013). Em Extensão, Uberlândia, v. 15, n. 2, p. 9-40, jul./dez. 2016 b.

CASTRO, E. G. de; BARCELLOS, S. B. Políticas públicas para a juventude rural brasileira. In: GRISA, C.; SCHNEIDER, S. (org.) Políticas Públicas de Desenvolvimento Rural no Brasil. Porto Alegre: Editora da UFRGS, 2015. p. 549-570.

CAZELlA, A. A.; CAPELESSO, A. J.; MEDEIROS, M.; TECCHIO, A.; SENCÉBÉ, Y.; BÚRIGO, F. L. Políticas Públicas de Desenvolvimento Rural no Brasil: o dilema entre inclusão produtiva e assistência social. Política e Sociedade, Florianópolis, vol. 15, Edição Especial, p. 48-79, 2016.

COELHO, P. S. A atuação da Unidade Regional da EMATER de Viçosa-MG: descrição e análise da ATER pública. 2016. 127 f. Dissertação (Mestrado em Extensão Rural), Universidade Federal de Viçosa, Viçosa, 2016.

EMATER-MG - EMPRESA DE ASSISTÊNCIA TÉCNICA E EXTENSÃO RURAL DO ESTADO DE MINAS GERAIS. Relatório de Atividades 2011. Belo Horizonte: EMATERMG. 2011. 50 p.

FUNDAÇÃO FACEV. Relatório de Gestão - 2016. Viçosa: FACEV. 2016. 34 p. (Relatório).

GIL, A. C. Métodos e Técnicas de Pesquisa Social. 6 ed. São Paulo: Atlas. 2008. 220 p.

GRISA, C.; SCHNEIDER, S. Três Gerações de Políticas Públicas para a Agricultura Familiar e Formas de Interação entre Sociedade e Estado no Brasil. Revista de Economia e Sociologia Rural. Piracicaba-SP, Vol. 52, Supl. 1, p. 125-146, 2014.

GUIMARÃES, M. do C. C. Processo Metodológico de Planejamento Participativo da Unidade Regional de Viçosa - EMATER - MG. In: THEODORO, S. H.; DUARTE, L. G.; 
VIANA, J. N. Agroecologia: um novo caminho para a extensão rural sustentável. Rio de Janeiro: Garamond, 2009, p. 151-180.

IBGE- Instituto Brasileiro de Geografia e Estatística. Censo Agropecuário 2017: resultados definitivos. Censo Agropecuário, Rio de Janeiro, v. 8, p. 1-105, 2019.

MARIN, J. O. B. Crédito Juvenil: a construção social da juventude rural moderna. Extensão Rural, Santa Maria, v.24, n.2, p. 22-36, abr./jun. 2017.

MARIN, J. O. B. PRONAF Jovem: as disjunções entre o ideal e o real. Revista de Economia e Sociologia Rural, Brasília, v.58, n.2, 19 p., jun. 2020.

MARINHO, C. M.; FREITAS, H. R. Utilização de Metodologias Participativas nos processos de Assistência Técnica e Extensão Rural (ATER): Fundamentos teórico-práticos.

Extramuros, Petrolina, Vol.3, n. 2, p. 10-28, jul. 2015.

MATTEI, L. O Papel e a Importância da Agricultura Familiar no Desenvolvimento Rural Brasileiro Contemporâneo. Revista Econômica do Nordeste, Fortaleza, v. 45, suplemento especial, p. 83-91, out./dez., 2014.

NEGRÃO, P.; CABRAL, F. A Semana do Fazendeiro: avanços e transformações. In: SOUSA, D. T. de; MORENO, A.; NEVES, C. A.; VIEIRA, L. B. (orgs.). Práticas e Reflexões na Extensão Universitária: a experiência da Universidade Federal de Viçosa. Viçosa: Editora UFV, 2017. p. 172-198.

RAUPP, F. M.; BEUREN, I. M. Metodologia da Pesquisa Aplicável às Ciências Sociais. In: BEUREN, I. M. Como elaborar trabalhos monográficos em contabilidade: teoria e prática. 3.ed. São Paulo: Atlas, 2006. p. 76 - 97.

SENA, F. J.; OLIVEIRA, F. M. de; MOREIRA, G. M. S. B.; SILVA, M. H. A. da; CAMPOS, S. A. C.; SOUZA, V. G. de (org.) Projeto Transformar: casos de sucessos dos jovens rurais mineiros. Belo Horizonte: EMATER-MG, 2010, 104 p.

SOUZA, S. B.; DOULA, S. M; CARMO, P. M. do. Jovens Rurais da Zona da Mata Mineira e Projetos de Vida Profissional. Redes (St. Cruz Sul, Online), v. 21, nº 1, p. 233 - 249, jan./abr. 2016.

SOUZA, S. B.; OLIVEIRA, M. L. R.; COELHO, F. M. G. A Atuação dos Clubes 4-S em Minas Gerais e a Ideia de Juventude Rural na EMATER-MG. Holos, Natal, Ano 32, vol.1, p. 142-152. 2016.

STALOCH, R.; ROCHA, I. de O. Agricultura Familiar e a Permanência no Campo: a experiência de um projeto realizado e a percepção de jovens sobre o município de Santa Terezinha (Santa Catarina). Extensão Rural, Santa Maria, v.25, n.3, p. 57-70, jul./set. 2018.

TROIAN, A. Jovens da região central do Rio Grande do Sul: perspectivas e políticas para permanência no meio rural. Revista IDEAS, Rio de Janeiro, v. 8, n. 1, p. 104-134, 2014. 